\title{
FORMULATION AND EVALUATION OF LORAZEPAM ENCAPSULATED COLLAGEN/PECTIN BUCCAL PATCH
}

\section{LAKSHMI V. S. ${ }^{\text {aa }}$, REVATHY B. MENON ${ }^{\square a}$, KEERTHANA RAJU ${ }^{\square a}$, AISWARYA M. U. ${ }^{\square a}$, SREEJA C. NAIR ${ }^{a^{*}}$}

aDepartment of Pharmaceutics, Amrita School of Pharmacy, Amrita Vishwa Vidyapeetham, AIMS Health Science Campus, Kochi, India Email: sreejacnair@aims.amrita.edu

Received: 29 May 2019, Revised and Accepted: 25 Jul 2019

\begin{abstract}
Objective: To formulate and characterize Lorazepam loaded buccal patches using mucoadhesive, biodegradable, natural polymers-pectin (hydrophilic) and collagen (lipophilic) for treating epileptic seizures.

Methods: Lorazepam loaded buccal patches were prepared by solvent casting method and were subjected to various Physico-chemical evaluation parameters to find the optimized buccal patch. The in vitro drug release study and ex vivo permeation study was carried out. The stability study and histopathological study of optimized Lorazepam loaded buccal patch was also carried out.

Results: From in vitro drug release study, it was found that Lorazepam loaded buccal patch (B4) exhibited maximum drug release of $96.16 \% \pm 0.07$ than other formulations at the end of $4 \mathrm{~h}$, indicating an initial burst release followed by sustained release with release kinetics as Higuchi diffusion model. Based on the in vitro drug release, \% drug content, \% swelling index, folding endurance, B4 formulation was considered as optimised formulation and was further characterized. Ex vivo permeation study revealed that the cumulative amount of drug permeated from optimised Lorazepam loaded buccal patch (B4) was higher $\left(3831.4 \pm 0.21 \mu \mathrm{g} / \mathrm{cm}^{2}\right)$ than marketed Midazolam buccal solution $\left(1724 \pm 0.12 \mu \mathrm{g} / \mathrm{cm}^{2}\right)$ and control drug solution $\left(895.42 \pm 0.07 \mu \mathrm{g} / \mathrm{cm}^{2}\right)$ with an enhancement ratio of 4.8 . B4 formulation also showed a higher flux value $\left(12.52 \pm 0.02 \mu \mathrm{g} / \mathrm{cm}^{2} / \mathrm{hr}\right)$ compared to marketed formulation $\left(5.732 \pm 0.01 \mu \mathrm{g} / \mathrm{cm}^{2}\right)$ and control drug solution $\left(2.563 \pm 0.03 \mu \mathrm{g} / \mathrm{cm}^{2}\right)$ of $\mathrm{P}<0.05$. The histopathological study using bovine buccal mucosa revealed that the B4 formulation is safe for buccal application. The stability study confirmed that B4 formulation is stable in both room and refrigeration conditions. Hence the formulated Lorazepam loaded buccal patch seems to be a promising carrier for the enhanced buccal delivery of Lorazepam in treating epileptic seizures.
\end{abstract}

Conclusion: The formulated Lorazepam loaded collagen/pectin buccal patch was found to be an efficient and stable route for the buccal delivery of Lorazepam in treating acute epileptic seizures which could be further explored scientifically.

Keywords: Lorazepam, Buccal patch, In vitro drug release, Steady-state flux, Epileptic seizures

(C) 2019 The Authors. Published by Innovare Academic Sciences Pvt Ltd. This is an open-access article under the CC BY license (http://creativecommons.org/licenses/by/4.0/) DOI: http://dx.doi.org/10.22159/ijap.2019v11i5.34366

\section{INTRODUCTION}

Epilepsy is a disorder of the central nervous system, precisely the brain, characterized by enduring predisposition and neuronal misfiring that ultimately results in epileptic seizures [1]. It causes the periodic loss of consciousness with abnormal electrical activity which either leads to convulsions or not leads to convulsions [2]. Epileptic seizure is an event of transient occurrence of signs and symptoms due to hypersynchronous activity of the neurons [3,4]. Commonly used medications for these epileptic seizures include oral dosage forms and intravenous dosage forms. These were found to be effective for management of chronic the epileptic seizures but were not effective to treat acute and immediate seizures [5-6]. Even though there are different modes of drug delivery systems all these were not able to save the golden hour, the time from the onset of rapid seizure to the time the person reaches the hospital [7]. Buccal drug delivery systems were found to produce this rapid onset of action as this region is immensely supplied with blood vessels and the drug directly reaches the systemic circulation surpassing the bypass effect. Among them the most effective one was found to buccal/mucosal patches incorporated with the drug [8-9]. The drug too should be such that it is adequately lipophilic, should possess high molecular weight, should be of low size and above all it should have rapid onset of action. All the benzodiazepenes category drugs like Midazolam, Diazepam were found to be effective all these exhibited several serious side effects especially sedation $[10,11]$. Therefore the aim of our study was to develop a drug delivery system made of natural polymers only and that incorporates a rapid-acting antiepileptic drug to resolve all these disadvantages and limitations of both the drug delivery system and the drug, effective for the management of acute seizures [12-15].

\section{MATERIALS AND METHODS}

\section{Materials and excipients}

Lake Chemicals Private Limited, Bangalore gifted us with Lorazeapm API. Pectin was obtained from CK'S products, Kochi. Collagen was obtained from Nitta Gelatin India ltd, Kochi. Olive oil was obtained from Thomson trading agencies, Kochi. All the chemicals used in the experiment were of analytical grade $[16,17]$.

\section{Preformulation studies}

Solubility

The solubility of drug was checked in different solvents such as methanol, distilled water, propanol, acetone, phosphate buffer saline (PBS) pH 6.8 [18].

\section{Melting point}

The melting point of the obtained drug sample indicates the purity of the sample. The melting point will be reduced in the presence of very few quantities of impurity. The melting point was found using open capillary method [19].

\section{Partition coefficient}

Partition coefficient of lorazepam in n-octanol was found out. The formed aqueous layer and organic phase were separated and the distribution of solute in both phase were determined by UV spectroscopy at $229 \mathrm{~nm}$ [20-23]

\section{Drug compatibility with excipients}

Excipients are added to improve the elegance of formulation, assist the progress of drug administration and promote bioavailability of drug for consistent release and protection from degradation. The excipients should be tentatively elected in order to get and productive dosage form [24-26].

\section{Fourier Transform Infra-Red (FTIR) spectroscopy study}

By FTIR spectrophotometer using $\mathrm{KBr}$ pellet method, FTIR spectra of drug and excipients were obtained to ascertain the compatibility between drug (lorazepam API) and selected polymer [27]. 


\section{Formulation of Lorazepam loaded collagen/pectin buccal patches}

In this study, lorazeapm loaded buccal patches were prepared by solvent casting method using a blend of biodegradable natural polymers like pectin (hydrophilic) and collagen (lipophilic) with olive oil as permeation enhancer and plasticizer [28]. Patches were prepared with a concentration of collagen ranging from $0.25-1.25 \%$, the percentage of pectin was kept constant at $1.5 \%$ after optimization and used $0.05 \mathrm{ml}$ of olive oil. The weighed quantities of pectin and collagens were dissolved separately in beakers containing $10 \mathrm{ml}$ distilled water [29-31]. $20 \mathrm{mg}$ (2\%) of drug was dissolved with olive oil and added small quantity of previously prepared collagen solution with proper continuous stirring. After complete dissolution of drug, remaining collagen solution was added followed by addition of pectin solution drop by drop and shaking after each drop to get a homogenous mixture. This was kept in a magnetic stirrer for 30 $\min$ at $600 \mathrm{rpm}$. Then the mixture was poured in a Petri dish of size $5 \times 3 \mathrm{~cm}^{2}$ initially coated with glycerine to avoid sticking of the patch [32-35]. The Petri dish was placed in hot air oven at temperature $40-45{ }^{\circ} \mathrm{C}$ for $24 \mathrm{~h}$ to get uniformly dried buccal patches. The formulation composition of lorazepam loaded buccal patches was shown in table 1.

Table 1: Formulation composition of Lorazeapam loaded collagen/pectin buccal patches

\begin{tabular}{lllllll}
\hline S. No. & Formulation code & Lorazepam (\%) & Pectin (\%) & Collagen (\%) & 0live oil (\%) & Distilled water(ml) \\
\hline 1. & B1 & 0.4 & 1.5 & 1.25 & 0.005 & qs.20 \\
2. & B2 & 0.4 & 1.5 & 1 & 0.005 & qs.20 \\
3. & B3 & 0.4 & 1.5 & 0.75 & 0.005 & qs.20 \\
4. & B & 0.4 & 1.5 & 0.5 & 0.005 & qs.20 \\
5. & B5 & 0.4 & 1.5 & 0.25 & 0.005 & qs.20 \\
\hline
\end{tabular}

\section{Preparation of backing membrane}

PVA-aluminium foil backing membrane was prepared by solvent casting film technique. It was casted by pouring $4 \% \mathrm{w} / \mathrm{v}$ aqueous solution of PVA on aluminum foil in Petri dishes at $42{ }^{\circ} \mathrm{C}$ and left for 10 hours to obtain dry film of drug impermeable backing membrane. The patches of suitable size were then cut and stored under suitable condition [36].

\section{Physicochemical evaluation of prepared Lorazepam loaded buccal patches}

The Physico-chemical evaluation studies of prepared lorazepam loaded patches were described below.

\section{Thickness uniformity of the patches}

Micrometer screw gauge was used to measure the thickness of three patches of $2 \times 2 \mathrm{~cm}^{2}$ size of formulation at three different places and mean value was determined [37].

\section{Uniformity of weight of the patches}

Digital balance was used to determine the weight of three patches of every formulation of size $2 \times 2 \mathrm{~cm}^{2}$ and individual weight was noted and calculated the average weight [38].

\section{Folding endurance}

Determination of folding endurance is by folding strip of patch of size $2 \times 2 \mathrm{~cm}^{2}$ at the same place till it broke. The number of time the patch could be folded at the same place without breaking gave the value of folding endurance [39].

\section{Surface $\mathbf{p H}$ determination}

Swelling index was determined by allowing three patches of each formulation of size $2 \times 2 \mathrm{~cm}^{2}$ to swell by keeping in contact with $1 \mathrm{ml}$ of distilled water for 1 hour at room temperature [40].

\section{Percentage swelling index}

Three patches of each formulation were cut into $2 \times 2 \mathrm{~cm}^{2}$ and weighed initially and kept immersed in $50 \mathrm{ml}$ PBS pH 6.8. Taken out and weighed at 5, 10, 30 and 60 min time intervals till a constant weight was obtained [41].

\section{Percentage of moisture absorption}

Physical stability of the patches was evaluated in high humidity conditions. Accurately weighed 3 patches were kept in a desicator containing aluminium chloride solution for $3 \mathrm{~d}$. The percentage of moisture content was determined by reweighing the patches [42].

\section{Drug content uniformity}

The drug-loaded patches of known weight $2 \times 2 \mathrm{~mm}$ dimension from 3 different areas were dissolved in $10 \mathrm{ml}$ of methanol and shaken until it dissolved. At $229 \mathrm{~nm}$ the absorbance of the diluted drug solution was measured. The polymer solution without drug served as blank [43].

\section{In vitro mucoadhesion study \\ In vitro mucoadhesion time}

Evaluation of Mucoadhesion properties of lorazepam loaded buccal patches was carried out by performing in vitro mucoadhesion study. Detachment time of lorazepam loaded buccal patches was determined. Initially, bovine buccal mucosa was kept in PBS pH 6.8 and stored in freezer and room temperature. Fixing of buccal mucosa was in such a way that mucosal surface placed in glass slide should face towards the the lorazeapm loaded buccal patch of $2 \times 2$ $\mathrm{cm}^{2}$ of each formulation. The above mucosa was then placed in the glass beaker containing $100 \mathrm{ml}$ of PBS pH 6.8 and was magnetically stirred at $100 \mathrm{rpm}$. In vitro mucoadhesion time was considered as time required for erosion of Lorazepam loaded buccal patches visually [44]

\section{In vitro mucoadhesive strength}

Specialised chemical balance helps to determine the force or stress used for the detachment of per $\mathrm{cm}$ square of area of bovine buccal mucosa in which the lorazeapm loaded buccal patches placed in between mucosae. The buccal mucosae were arranged in such a way that on a clear glass surface of one side of balance a section of buccal mucosa was tied with help of a rubber band and another mucosa placed in inverted position to that of first so that both mucosal surfaces face each other. Each formulation of lorazepam loaded buccal patch of size $2 \times 2 \mathrm{~cm}^{2}$ was kept in between the two mucosae. Measurement of different formulation was noted from different mucosae. Mucoadhesive strength was determined from detachment of two mucosae by increasing the weight on the other side of pan [45].

\section{In vitro drug release study}

The in vitro drug release studies of different formulations of lorazepam loaded buccal patches were done by static dissolution method. The apparatus was set up by introducing an open end tube aligned vertically to a beaker containing $50 \mathrm{ml}$ of PBS pH 6.8 which acts as receptor compartment. The open end tube was tied with a cellophane membrane (molecular weight 12000-14000 D) on one side which resembles the membrane acting as a barrier within the body, so that only the tip touches the surface of buffer solution. The reaction conditions were standardised throughout the study. The receptor compartment was filled with $50 \mathrm{ml}$ of PBS 6.8 and the donor compartment with $2 \mathrm{~cm}^{2}$ of lorazepam loaded buccal patch. The beaker was placed on a magnetic stirrer for a definite study time and $1 \mathrm{ml}$ of samples was withdrawn at regular intervals. For each withdrawal, $1 \mathrm{ml}$ of fresh PBS pH 6.8 was replaced into the beaker and the collected samples were diluted using the same. The percentage of drug released in the receptor medium was 
spectrometrically analysed using UV visible spectrophotometer at $229 \mathrm{~nm}$. All the analysis was done triplicate [46].

\section{Kinetic models of in vitro drug release study}

The data obtained from in vitro release studies of lorazepam buccal patches were fitted to various kinetic models such as Zero order, First order, Higuchi plot and Koresmeyer-peppas plot to identify the model of drug release of lorazepam buccal patches.

\section{Ex vivo permeation study}

\section{Buccal mucosa preparation}

The bovine buccal mucosal region was collected from a local slaughter house at morning and the buccal mucosa was cleaned with normal saline and used for the study by noon. The underlying fat deposits were initially excised off uniformly and the mucosal membrane was separated out. The buccal mucosal layer retaining all the layers was allowed to equilibrate for one hour in receptor buffer to retain its properties as live tissue. Later on the mucosa was stored in containers partly filled with normal saline solution until further use [47].

\section{Preparation of set up in franz diffusion cell}

The ex vivo permeation comparison study of optimised lorazepam loaded buccal patch (B4), midazolam buccal solution (marketed formulation) and control drug solution (drug in buffer $\mathrm{pH} 6.8$ were done in franz diffusion cell having a donar and receptor compartment in it. The receptor compartment was loaded in PBS pH $6.8(7 \mathrm{ml})$ and bovine buccal mucosa of size $2.54 \mathrm{~cm}^{2}$ was mounted between the donor and receptor compartments. The set up was maintained under sink condition throughout the study period for $6 \mathrm{~h}$ at a constant temperature of $37 \pm 1^{\circ} \mathrm{C}$. A measured length of $2 \mathrm{~cm}^{2}$ of optimised (B4) was placed on the donor compartment and ex vivo permeation study was carried out. At definite intervals, $0.2 \mathrm{ml}$ of sample was withdrawn from donor compartment with long needles and replaced with fresh $0.2 \mathrm{ml}$ of PBS $\mathrm{pH}$ 6.8. The study was done for $6 \mathrm{~h}$ and same experiment was repeated for $5 \mathrm{mg} / \mathrm{ml}$ of midazolam buccal solution (marketed formulation) and $4 \mathrm{mg} / \mathrm{ml}$ of control drug solution (drug in PBS pH 6.8) was done. After the dilution of samples suitably, samples are spectrophotometrically analysed by UV-VIS spectrophotometer at $229 \mathrm{~nm}$ and cumulative amount of drug permeated per $\mathrm{cm}^{2}$ were estimated and statistical interpretation using student $\mathrm{T}$ test was performed [48].

\section{Steady-state flux determination}

The data obtained from ex vivo permeation were used to determine the permeation parameters like steady-state flux (J), enhancement ratio and statistical analysis by Student's t-test was performed.

\section{Histopathological study}

The buccal mucosal membrane was isolated and prepared in a similar to that of ex vivo permeation study of lorazepam loaded buccal patch. The treated bovine buccal mucosa was subjected to $6 \mathrm{~h}$ of ex vivo permeation study and histopathological examination were done to identify any visual damages occurring to the normal mucosal surface after treatment with the developed lorazepam loaded buccal patch [49].

\section{Treatment of bovine buccal mucosa for histopathological study}

Histopathological study was done for three formulations. Previously treated bovine buccal mucosa was subjected to $5 \mathrm{~h}$ of ex vivo permeation study of optimised lorazepam loaded buccal patch (B4), midazolam buccal solution (marketed formulation), control drug solution (drug in PBS pH 6.8) and was compared with that of normal buccal mucosa which serves as normal control. The tissue taken after permeation study was initially fixed in $10 \%$ formalin solution. The preserved live tissue were equally cut into $5 \mu \mathrm{m}$ containing sections and further stained with hematoxylin and eosin and analysed using light microscope [50].

\section{Fourier transform infrared spectroscopy}

The FTIR spectrum of optimized lorazepam loaded buccal patch was compared with FTIR spectra of drug and excipients to check the compatibility among them [51].

\section{Scanning electron microscopy (SEM)}

The SEM image of optimised lorazepam loaded buccal patch (B4) was analysed by powdering the sample and further diluting with distilled water to examine under SEM (Joel jsm-64901a analytic SE) [52].

\section{Stability study}

The optimised lorazepam loaded buccal patch (B4) was stored for $45 \mathrm{~d}$ and was subjected to various stability studies within refrigerator $\left(4 \pm 2{ }^{\circ} \mathrm{C}\right)$ and room temperature $\left(29 \pm 2{ }^{\circ} \mathrm{C}\right)$ in triplicate. The samples were taken at frequent intervals and assessed for drug content release at various time intervals were calculated [53].

\section{RESULTS AND DISCUSSION}

\section{Preformulation studies}

\section{Solubility of Lorazepam}

Lorazepam is soluble in methanol, propanol and phosphate buffer saline (PBS pH 6.8) and is slightly soluble in distilled water and acetone.

\section{Melting point}

The melting point of the drug was determined by capillary method and was found to be $192-194{ }^{\circ} \mathrm{C}$ and was in accordance with the monograph IP.

\section{Partition coefficient}

Determination of Partition coefficient of the drug was carried out and was found to be 3.75 . It shows that the drug is practically highly lipophilic and insoluble in water [54].

\section{Fourier transform infrared (FTIR) spectroscopy}

The FTIR spectra of the drug Lorazepam and excipients, collagen and pectin were determined.

In FTIR spectra of lorazepam a strong peak at $3549 \mathrm{~cm}^{-1}$ shows the presence of the hydroxy group. The most intense band present at $1739 \mathrm{~cm}^{-1}$ is due to the presence of a carbonyl group $(C=0)$. A peak at $673 \mathrm{~cm}^{-1}$ indicated presence of aromatic ring fig. 1A. FTIR spectra of collagen showed strong peak at $1650 \mathrm{~cm}^{-1}$. It indicated the presence of amide I carbonyl stretching. Amide II stretching is also present at $1560 \mathrm{~cm}^{-1}$. Three weak bonds are also present that represents amide III at $1245 \mathrm{~cm}^{-1}$ fig. $1 \mathrm{~B}$.

FTIR spectra of pectin showed a broader peak at $3756 \mathrm{~cm}^{-1}$ indicated the presence of hydroxyl functional group. A characteristic peak at $1161 \mathrm{~cm}^{-1}$ indicated the presence of $\mathrm{C}-\mathrm{O}$ aluminum group fig. $1 \mathrm{C}$.

FTIR spectrum of optimized Lorazepam loaded buccal patch was determined by $\mathrm{KBr}$ pellet method. FTIR spectra of optimized Lorazepam loaded buccal patch showed a broad peak at $3612 \mathrm{~cm}^{-1}$ indicated the presence of a hydroxy-functional group of Lorazepam, collagen, and pectin. A peak at $1691 \mathrm{~cm}^{-1}$ indicates the presence of ketone (carbonyl) functional group of Lorazepam. A peak at 1151 $\mathrm{cm}^{-1}$ indicates the presence of $\mathrm{C}-0$ group of pectin fig. 1D.

From the peaks, it was found that same peaks were retained as that of the peaks of Lorazepam and the excipients (collagen and pectin). No additional peaks were obtained. This confirmed the compatibility between the drug Lorazepam and the excipients.

\section{Formulation of lorazepam loaded buccal patch}

In this study, Lorazepam loaded buccal patches were prepared by solvent casting method using natural biodegradable polymers like collagen and pectin with olive oil as natural permeation enhancer and plasticizer. The concentration of olive oil was optimized. The patches were prepared with $0.25-1.25 \%$ and pectin $1.5 \%$. The percentage of pectin was kept constant at $1.5 \%$. As the concentration of collagen increased to $1.25 \%$ the patches became harder and brittle in nature. When the patches were made with 0.50 to $1 \%$ collagen and $1.5 \%$ pectin, the patches possessed good flexibility and were easily removable from the Petri dish. But when the concentration of collagen was reduced to $0.25 \%$, the patch was difficult to remove from the Petri dish and was brittle in nature. All the patches prepared were translucent in nature. 


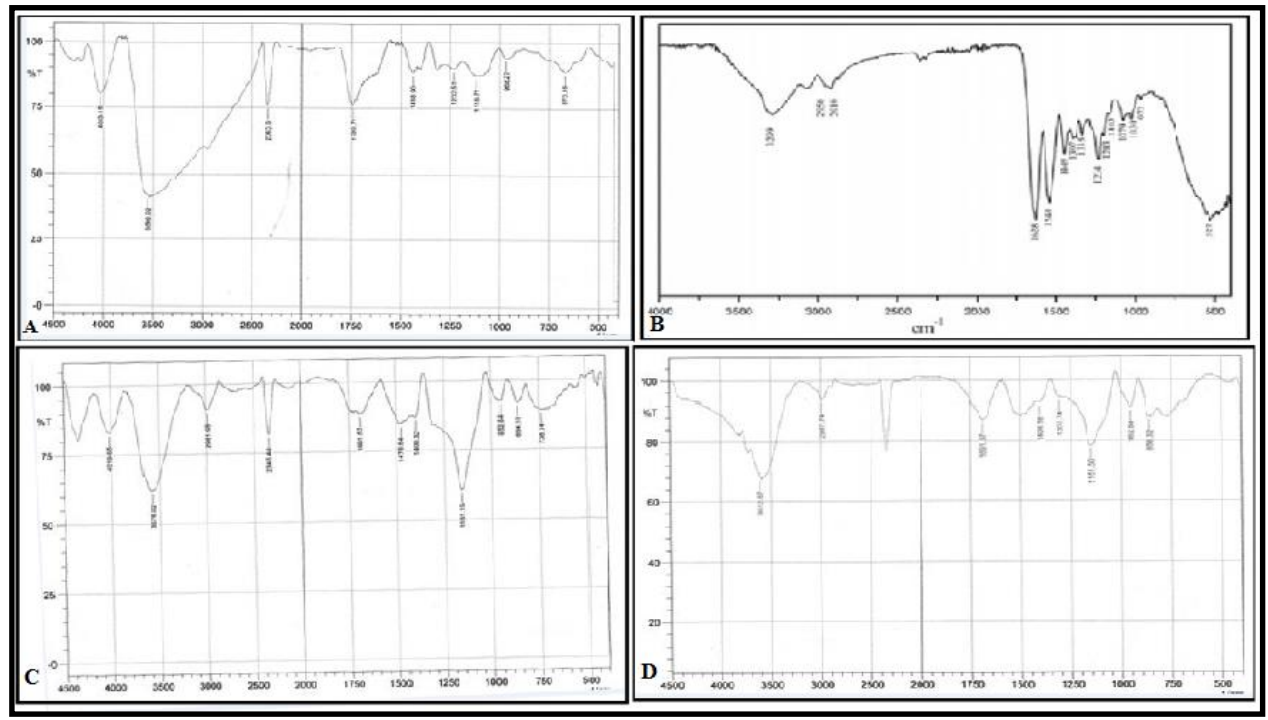

Fig. 1: A) FTIR spectrum of Lorazepam API, B) FTIR spectrum of collagen, C) FTIR spectrum of pectin, D) FTIR spectrum of optimized lorazepam loaded buccal patch (B4)
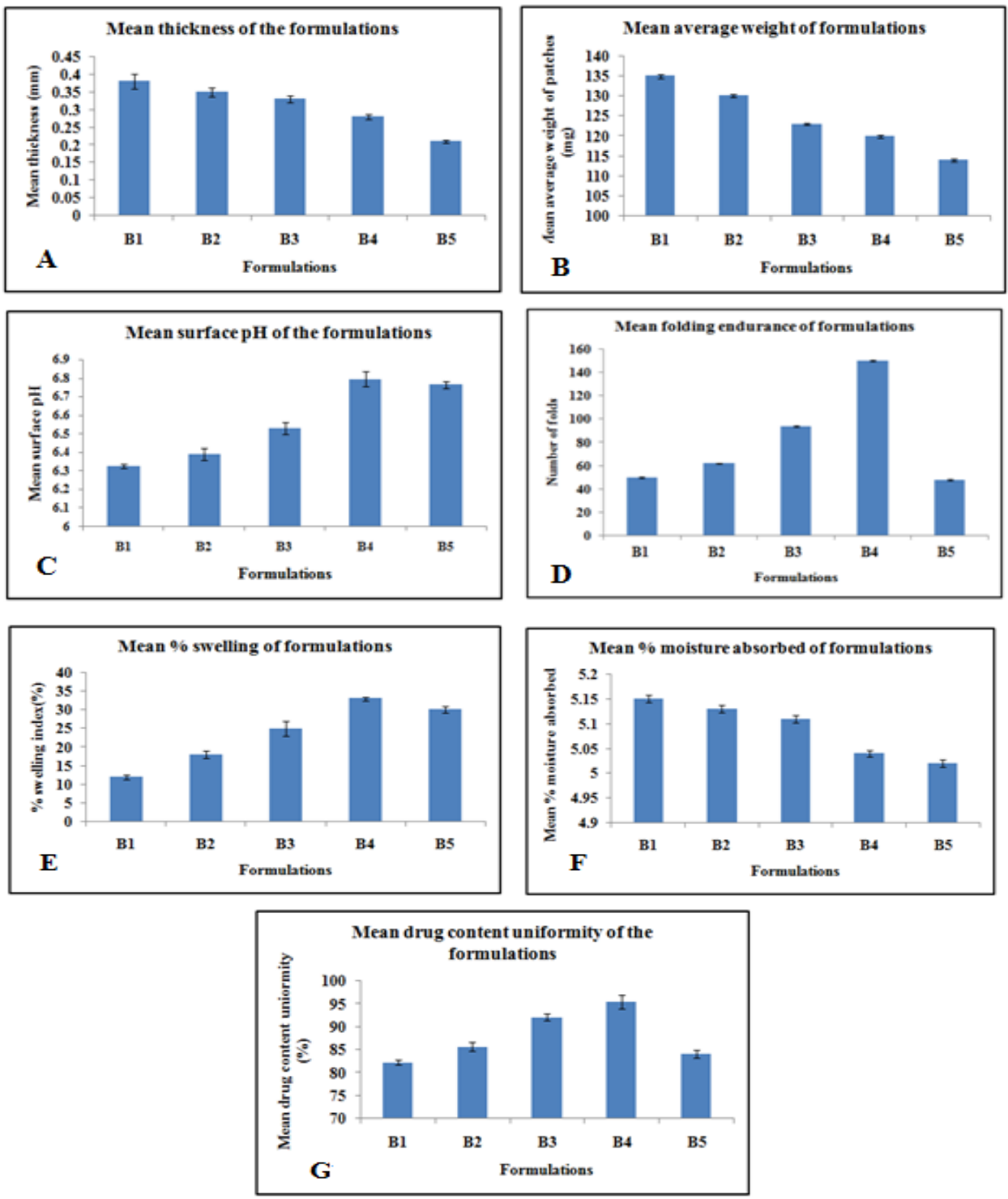

Fig. 2: A) Mean thickness B) Mean average weight, C) Mean surface pH, D) mean folding endurance, E) Mean \% swelling, F) Mean \% moisture absorbed, G) Mean drug content uniformity, (Values are expressed as mean \pm standard deviation, $n=3$ ) 
Physico-chemical evaluation of prepared lorazepam loaded buccal patches

\section{Thickness uniformity of patches}

From the thickness studies it was found that the mean thickness of the patches increases with increase in the concentration of the collagen polymer from $0.25-1.25 \%$, shown in fig. 2(a). The thickness of the patches was found to be satisfactory as the area of administration is the buccal region [54].

\section{Uniformity of weight of patches}

The average weight of the patches varied from $114 \mathrm{mg} \pm 0.70$ to 130 $\mathrm{mg} \pm 0.71$ for B1-B5 as given in fig. 2(b).

\section{Folding endurance}

The folding endurance study confirmed that the patches did not undergo cracking even after it was folded for more than 100 times. The folding endurance values did not change much when a comparison was made between bare patches and the drug-loaded patches in fig. 2 (c) [55].

\section{Surface pH determination}

The surface $\mathrm{pH}$ of all the formulations B1-B5 was found to in the range 6.32 $\pm 0.035-6.79 \pm 0.007$ (fig. 2 (d)) indicating that the formulations were non-irritant to buccal mucosa [56].

\section{Percentage swelling index}

The swelling index of the patches B1-B5 ranged from $12 \% \pm 0.70$ to $30 \% \pm 2.12$ shown in fig. 2 (e). As the concentration of collagen increased more than an optimum concentration, the swelling property decreased. B4 formulation got maximum swelling index. The olive oil (plasticizer) also enhanced the swelling properties of the formulations [57].

\section{Percentage moisture absorption}

The percentage moisture absorption of Lorazepam encapsulated patch was found to be between $5.15 \% \pm 0.07 \%$ to $5.02 \% \pm 0.14$ as shown in fig. 2 (f). The lesser the percentage moisture absorption, the more the patches will be stable at humid conditions [58].

\section{Drug content uniformity}

All the formulations exhibited good drug content. Among them, B4 exhibited the highest drug content with $95.49 \pm 0.071 \%$ as shown in fig. 2 (g) [59].

\section{In vitro mucoadhesion studies}

\section{In vitro mucoadhesion time}

Mucoadhesion time taken for the Lorazepam loaded buccal patches to detach from the bovine buccal mucosa was noted. The mucoadhesion time taken for B4 formulation was found to be satisfactory when an optimum concentration of collagen was used, as shown in fig. 3(a). Mucoadhesion property of the patch is imparted by the presence of natural polymers like collagen and pectin. A higher value of mucoadhesion of optimized Lorazepam loaded buccal patch indicates that it can be attached to the bovine buccal mucosa for longer period of time with less risk of salivary clearance and provided a sustained effect for few hours [60].

\section{In vitro mucoadhesion strength}

Mucoadhesion study was carried out for a longer time at the site of absorption to ensure that the formulation have the ability to adhere to the buccal mucosal membrane. The mucoadhesive character was exhibited due to the presence the two natural polymers collagen and pectin. The mucoadhesive strength of the optimized Lorazepam buccal patch (B4) was found to be optimum to produce its action shown in fig. 3(b).

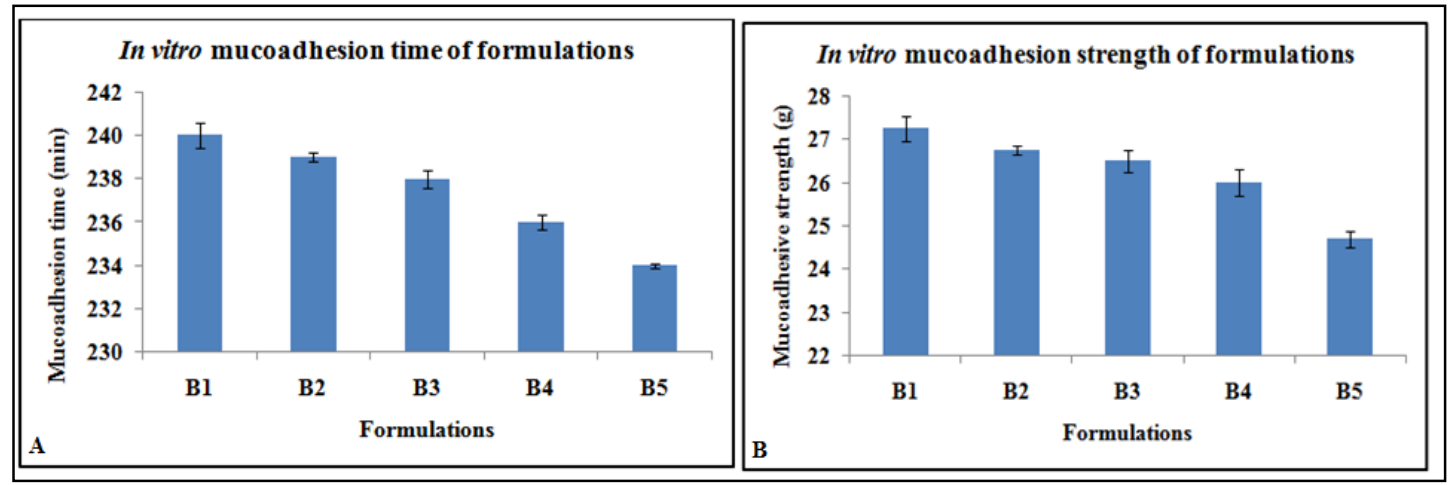

Fig. 3: A) In vitro mucoadhesion time, B) In vitro mucoadhesion strength, (Values are expressed as mean \pm standard deviation, $\mathrm{n}=3$ )

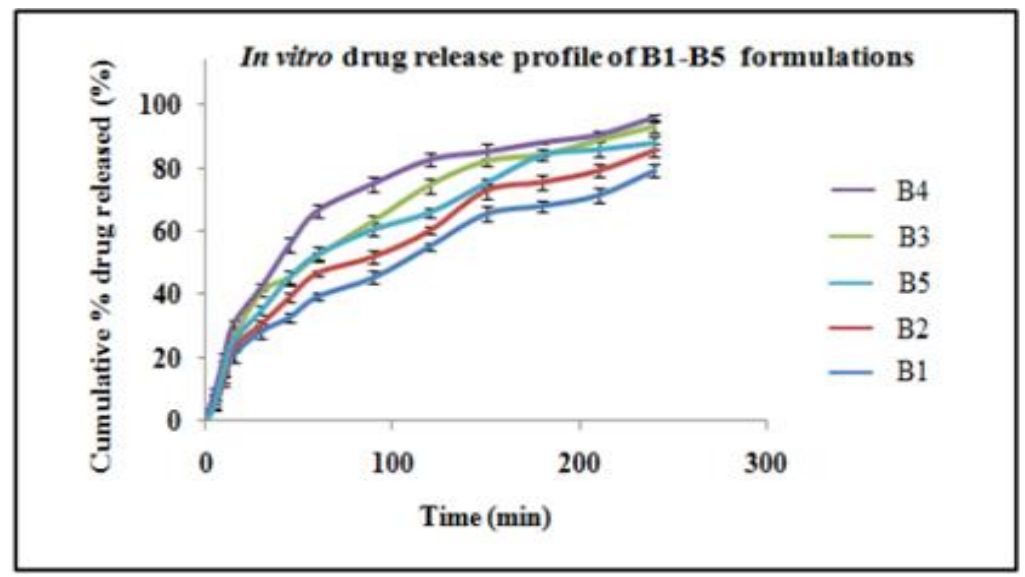

Fig. 4: In vitro drug release of prepared B1-B5 formulations, (Values are expressed as mean \pm standard deviation, $\mathrm{n}=3$ ) 


\section{In vitro drug release studies}

The in vitro drug release study gave an idea regarding the amount of the drug that is available for absorption into the systemic circulation. The release profile of drug predicts the in vivo behavior of the drug in the circulation. The $\mathrm{pH}$ of the buccal fluid lies between 6.5-6.8. So the release studies were carried out using phosphate buffer solution of 6.8. The cumulative amount of drug released from each formulation $\mathrm{v} / \mathrm{s}$ time curve was plotted. The cumulative percentage of drug released for all formulation varied from $79.24 \pm 0.14 \%$ to $96.16 \pm 0.07 \%$ at the end of $4 \mathrm{~h}$. After $4 \mathrm{~h}$, the patch lost its stability and integrity and was not suitable for further release study. The B4 formulation showed a maximum release of $96.16 \pm 0.07$
$\%$ when compared to other formulations, shown in fig. 4 . The drug leached out from the surface of the patch into the phosphate buffer solution [61].

\section{Kinetic model of in vitro drug release study}

The drug release profile of optimized Lorazepam loaded collagen/pectin buccal patch was attributed to different kinetic models like zero order, first order, Higuchi's diffusion model and Korsmeyer peppas plot to interpret drug release by kinetic modeling. The release kinetics of the drug Lorazepam was found to be Zero-order and was best fitted with Higuchi diffusion model with the highest regression coefficient value, $\mathrm{R}^{2}=0.978$ (fig. 5) [62].

Table 2: In vitro release model fitting data of optimized Lorazepam loaded buccal patch (B4)

\begin{tabular}{llllc}
\hline Zero order release plot & First order release plot & Higuchi plot & \multicolumn{2}{c}{ Koresmeyer peppas plot } \\
\hline $\mathrm{R}^{2}$ & $\mathrm{R}^{2}$ & $\mathrm{R}^{2}$ & $\mathrm{n}$ & $\mathrm{R}^{2}$ \\
0.978 & 0.758 & 0.978 & 6.375 & 0.909 \\
\hline
\end{tabular}

Ex vivo permeation comparison study and steady-state flux determination

For the optimized Lorazepam loaded buccal patch (B4) ex vivo permeation study was performed in franz diffusion cell using buccal mucosa of bovine. Each buccal mucosa of bovine resembled the human buccal mucosa hence the ex vivo studies were done using bovine buccal mucosa. Each bovine buccal mucosa was treated with optimized Lorazepam loaded buccal patch (B4), Midazolam buccal solution (marketed formulation) and control drug solution (drug in PBS $\mathrm{pH}$ 6.8). At a fixed time intervals from the receptor compartment $0.2 \mathrm{ml}$ samples were withdrawn. These were analyzed and the cumulative drug permeated was plotted against time. The cumulative amount of drug permeated from the optimized Lorazepam loaded buccal patch (B4) was found to be $3831.19 \mu \mathrm{g} / \mathrm{cm}^{2}$ at the end of $4 \mathrm{~h}$, from Midazolam buccal solution (marketed formulation) was found to be $1724.12 \mu \mathrm{g} / \mathrm{cm}^{2}$ and from control drug solution (drug in PBS pH 6.8) was found to be 895.43 $\mu \mathrm{g} / \mathrm{cm}^{2}$ at the end of $4 \mathrm{~h}$. This means that the amount of drug permeated from optimized Lorazepam loaded buccal patch (B4) formulation was higher compared to other formulation with an enhancement ratio of 4.88 (fig. 6). Similarly the enhancement ratio of Midazolam buccal solution (marketed formulation) was found to be 2.23 [63].

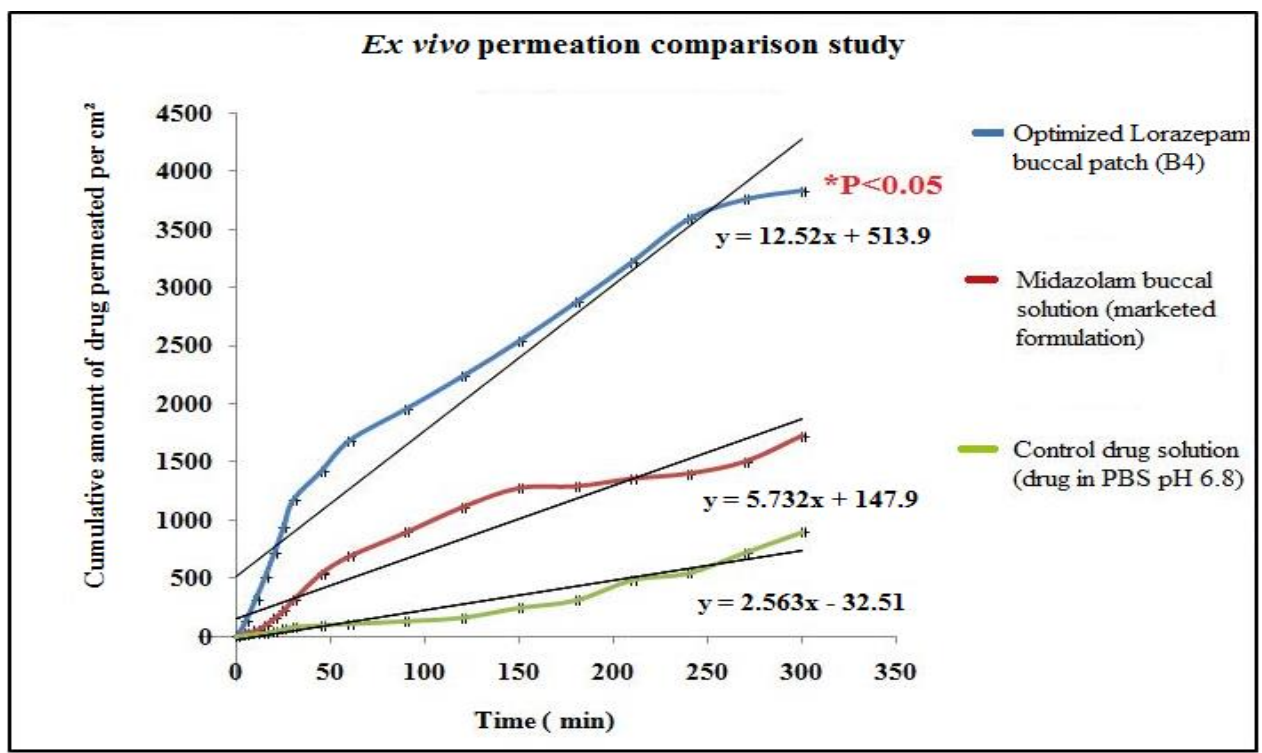

Fig. 6: Ex vivo permeation comparison study of optimized Lorazepam loaded buccal patch (B4) and the Midazolam buccal solution (marketed formulation) with control drug solution (drug in PBS pH 6.8), (Values are expressed as mean \pm standard deviation, $n=3$ )

Table 3: Ex vivo permeation study of optimized Lorazepam loaded buccal patch (B4), Midazoalm buccal solution (marketed formulation), and control drug solution (drug in PBS pH 6.8)

\begin{tabular}{lllll}
\hline S. No. & Parameters & $\begin{array}{l}\text { Optimized Lorazepam loaded } \\
\text { buccal patch (B4) }\end{array}$ & $\begin{array}{l}\text { Midazolam buccal solution } \\
\text { (marketed formulation) }\end{array}$ & $\begin{array}{l}\text { Control drug solution (drug } \\
\text { in PBS pH 6.8) }\end{array}$ \\
\hline 1 & $\begin{array}{l}\text { Steady state flux-J } \\
\left(\mu \mathrm{g} / \mathrm{cm}^{2} / \mathrm{h}\right)\end{array}$ & $12.52 \pm 0.02$ & $5.732 \pm 0.01$ & $2.563 \pm 0.03$ \\
& & & 2.23 & - \\
\hline
\end{tabular}

(Values are expressed as mean \pm standard deviation, $n=3$ ) 
From the data obtained from the ex vivo permeation study, the slope gives the steady-state flux of the three formulations as shown in table 3 .

The steady-state flux value was higher for the optimized Lorazepam loaded buccal patch $12.52 \pm 0.02 \mu \mathrm{g} / \mathrm{cm}^{2} / \mathrm{hr}$ than the Midazolam buccal solution (marketed formulation) $5.732 \pm 0.01 \mu \mathrm{g} / \mathrm{cm}^{2} / \mathrm{hr}$ and the control drug solution (drug in PBS pH 6.8) $2.563 \pm 0.03 \mu \mathrm{g} / \mathrm{cm}^{2} / \mathrm{h}$.
The enhancement ratio was obtained by the ratio of the steady-state flux values optimized Lorazepam loaded the buccal patch and the Midazolam buccal solution (marketed formulation) with that of the control drug solution $[63,64]$. The enhancement ratio of the optimized Lorazepam loaded buccal patch was found to be 4.88 and that of Midazolam buccal solution (marketed formulation) was found to be 2.23 (fig. 7).

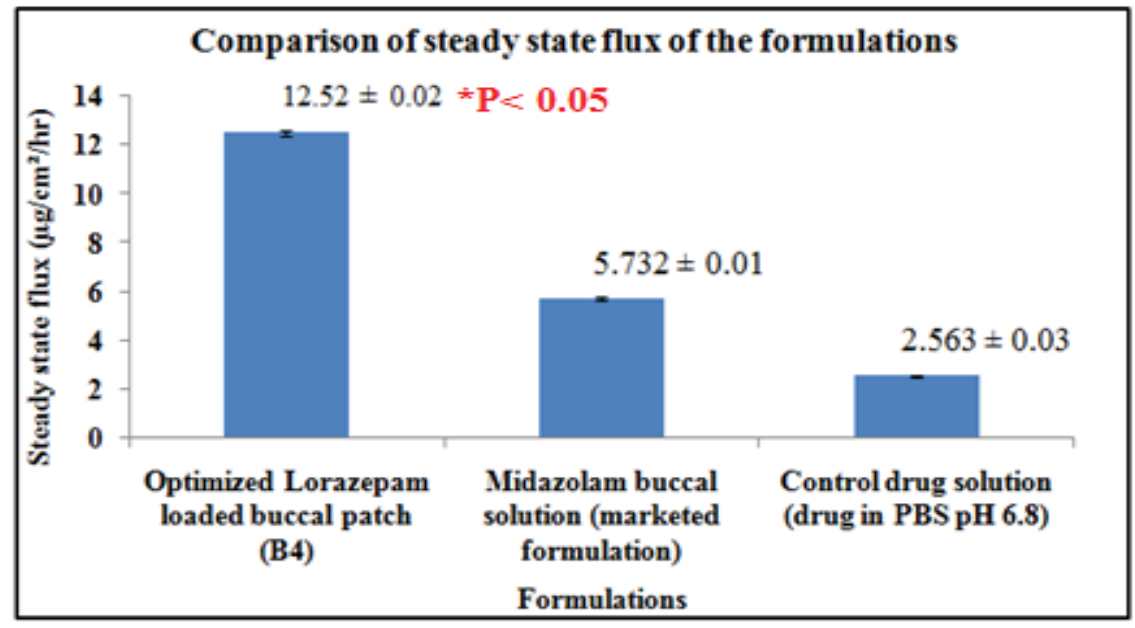

Fig. 7: Comparison of the steady state flux values of optimized Lorazepam loaded buccal patch, the midazolam buccal solution (marketed formulation) and the control drug solution

\section{Statistical analysis by student's t-test}

The statistical analysis by Student's t-test were performed for the steadystate flux values of the optimized Lorazepam loaded buccal patch, the Midazolam buccal solution (marketed formulation) and the control drug solution (drug in PS pH 6.8). The statistical analysis by Student's t-test revealed that there was significant difference in the steady-state flux value of the optimized Lorazepam loaded buccal patch (B4) and the Midazolam buccal solution (marketed formulation) with that of the control drug solution (drug in $\mathrm{PBS} \mathrm{pH}$ 6.8), where $(\mathrm{P}<0.05)$ thus very significant. Hence the difference was statistically significant [65].

\section{Histopathological studies}

The bovine buccal mucosa, which was subjected to ex vivo permeation studies were assessed for histopathological studies. The fig. $8[\mathrm{~B}, \mathrm{C}, \mathrm{D}]$ showed that there were no significant changes observed in the histological pattern of the mucosa treated with optimized Lorazepam loaded buccal patch, Midazolam buccal solution (marketed formulation) and control drug solution (Lorazepam in PBS pH 6.8) as compared with the normal buccal mucosa shown in fig. $8[\mathrm{~A}]$. Hence, Lorazepam loaded buccal patch did not cause any irritation and was safe for the buccal application.
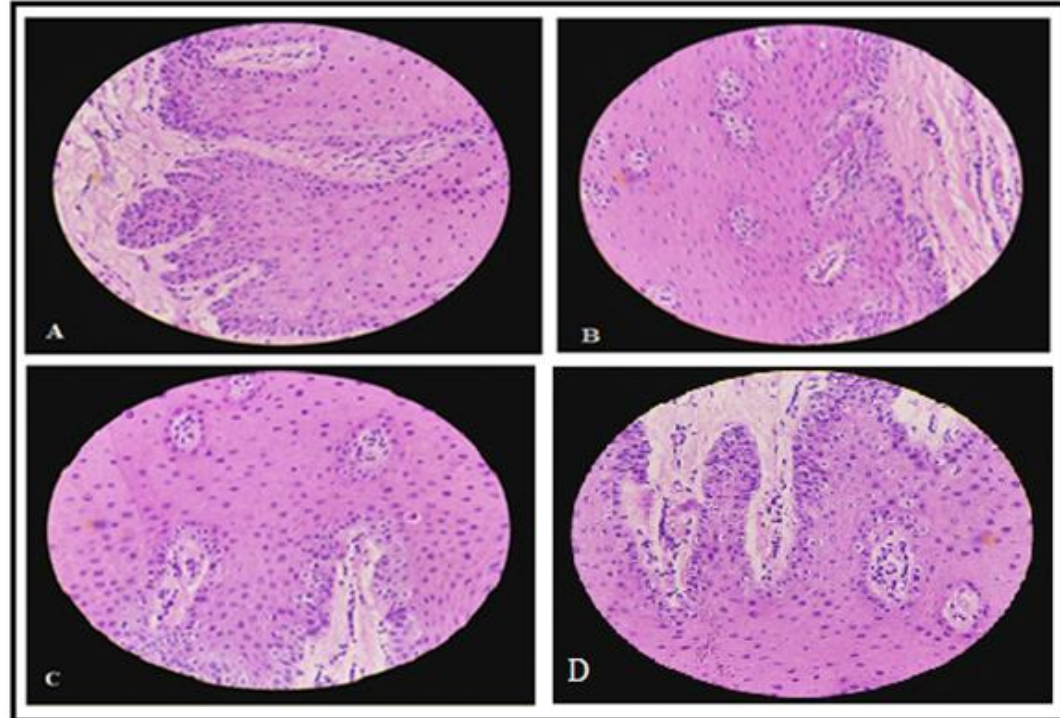

(Scale bar $=35$ microns with $40 x$ magnification)

Fig. 8: Histopathological studies of the buccal mucosa A) Normal buccal mucosa, B) Buccal mucosa with optimized Lorazepam loaded buccal patch (B4), C) Buccal mucosa treated with Midazolam buccal solution (marketed formulation), D) Buccal mucosa treated with control solution (Lorazepam in PBS pH 6.8) 


\section{Scanning electron microscopy (SEM)}

The SEM study was carried out for optimized Lorazepam loaded buccal patch (B4) in order to examine the morphology of the buccal patch. The surface morphology of Lorazepam incorporated collagen/pecin buccal patch, indicates that surface is smooth and drug is found dispersed within the matrix shown im fig. 9 [66].

\section{Stability study}

The stability study of the optimized Lorazepam loaded buccal patch (B4) was carried out for $45 \mathrm{~d}$ at room temperature $\left(30 \pm 2{ }^{\circ} \mathrm{C}\right)$ and at refrigerator temperature $\left(4 \pm 2{ }^{\circ} \mathrm{C}\right)$ and its physical changes like colour, flexibility, texture, drug content and \% drug release was estimated at an interval of one week [67]. The physical appearance of the patch was retained that it did not show any change on comparing with the freshly prepared patch at refrigeration and room temperature. The drug content and cumulative percentage drug release were determined for the patches at $7^{\text {th }}, 15^{\text {th }}, 30^{\text {th }}, 45^{\text {th }}$ day (fig. 10 and fig. 11). The results of the study indicated that there were no significant changes observed in room temperature and refrigerated temperature. The stability study revealed that the optimized Lorazepam loaded buccal patch B4 of 1\% collagen concentration remained stable at room temperature and refrigerated temperature [68].

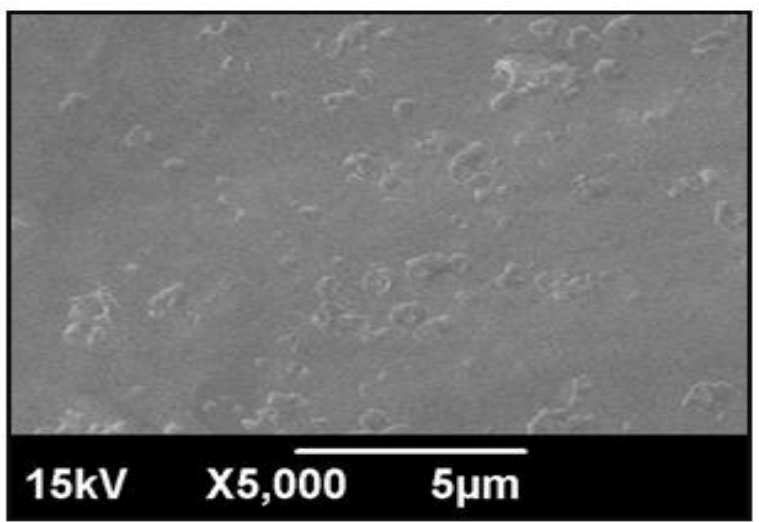

Fig. 9: SEM image of Lorazepam incorporated buccal patch

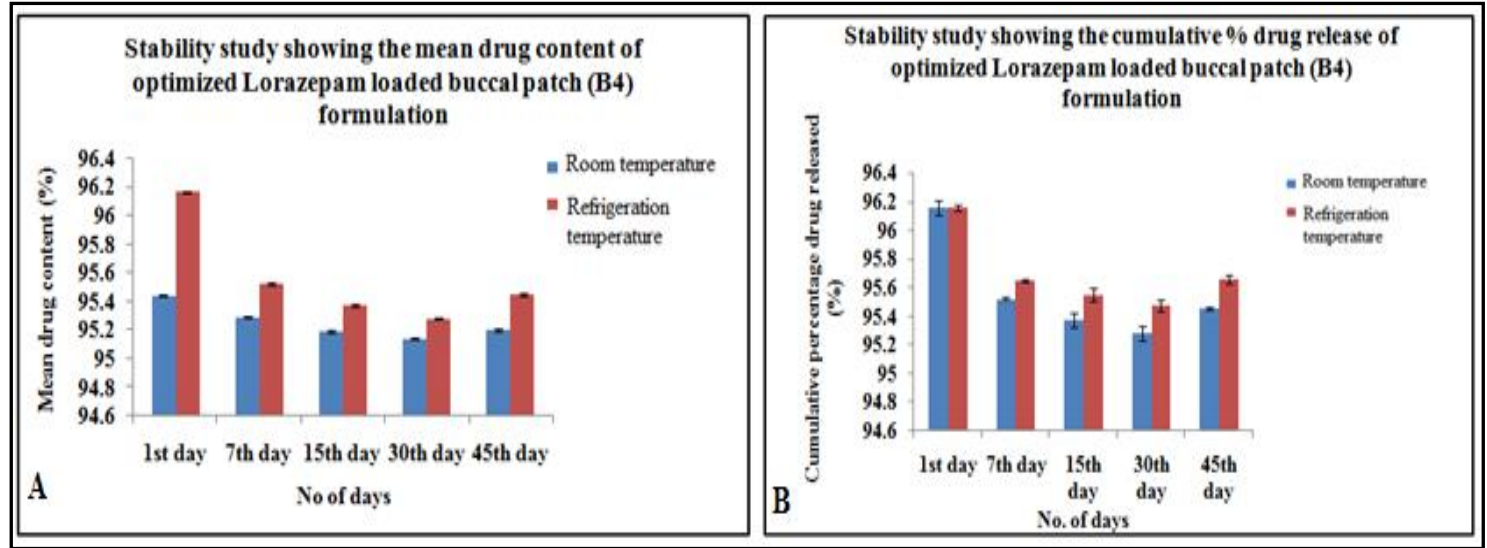

Fig. 11: A) Stability data showing the mean drug content of optimized Lorazepam loaded buccal patch (B4) formulation, B) Stability data showing the cumulative \% drug release of optimized Lorazepam loaded bucccal patch (B4) formulation, (values are expressed as mean \pm Standard deviation, $n=3$ )

\section{CONCLUSION}

Epilepsy is a chronic neurologic disorder that causes unprovoked recurrent seizures. Even though there have been different modes of drug delivery systems developed to treat the epileptic seizures, none of them proved to be fully effective. Buccal patches, as a potential drug delivery systems, gained relevance in the pharmaceutical area as a novel, patient-friendly, convenient and excellent forms of accessible products. Lorazepam loaded buccal patches were prepared by solvent casting method using a blend of biodegradable, biocompatible natural polymers like pectin (hydrophilic) and collagen (lipophilic) with olive oil as permeation enhancer and plasticizer. The prepared unidirectional buccal patches of Lorazepam provided a maximum drug release within specified mucoadhesion period and possessed a higher permeation coefficient/flux and enhancement ratio as compared to the Midazolam buccal solution (marketed formulation) and control drug solution (drug in PBS pH 6.8). Thus the formulated Lorazepam loaded collagen/pectin buccal patch was found to be an efficient and stable route for the buccal delivery of Lorazepam in treating acute epileptic seizures which could be further explored scientifically.

\section{AUTHORS CONTRIBUTIONS}

All the author have contributed equally

\section{CONFLICT OF INTERESTS}

Declared none

\section{REFERENCES}

1. Annegers JF, Hauser WA, Elveback LR. Remission of seizures and relapse in patients with epilepsy. Epilepsia 1979;20:729-37.

2. Arroyo S, Kramer G. Treating epilepsy in the elderly: safety considerations. Drug Saf 200;24:991-1015.

3. Desai C. Meyler's side effects of drugs: the international encyclopedia of adverse drug reactions and interactions. Indian J Pharmacol 2016;48:224.

4. Mark M. Recent advances in epilepsy. J Neurol 2017;264:1811-24.

5. Suruchi S, Vaishali D. Epilepsy-a comprehensive review. Int J Pharm Res Rev 2013;2:61-80.

6. Khanna R, Agarwal SP, Ahuja A. Mucoadhesive buccal delivery: a potential alternative to conventional therapy. Indian J Pharm Sci 1998;60:1-11.

7. Sudhir M, Buchi NN. Development of zolmitriptan mouth dissolving films: formulation, mechanical properties and in vitro drug release studies. Asian J Pharm Clin Res 2019;12:273-9.

8. Madhavi BR, Murthy VSN, Rani AP, Kumar GD. Buccal film drug delivery system: an innovative and emerging technology. J Mol Pharm Org Process Res 2013;1:107.

9. Reddy RJ, Anjum M, Hussain MA. A comprehensive review on buccal drug delivery system. Am J Adv Drug Delivery 2013;1:300-12.

10. Michael R, Joseph E, Guido B, Frank A. Oral mucosa harvest: an overview of anatomic and biologic consideration. EAU-EBU Update Series; 2007. p. 179-87. 
11. Verma P, Thakur S, Deshmukh K, Verma S. Routes of drug administration. Int J Pharm Sci Res 2010;1:54-109.

12. Sellappan V, Sumanjali D. Buccal penetration enhancers-an overview. Asian J Pharm Clin Res 2013;6:39-47.

13. Harris D, Robinson JR. Drug delivery via the mucous membranes of the oral cavity. J Pharm Sci 1992:81:1-10.

14. Lester DR Thompson. Data set for the reporting of oral cavity carcinoma. Arch Pathol Lab Med 2019;143:439-46.

15. Ali AMA, Sarhan HA, Magdy T. Preparation and characterization of phenytoin sodium niosomes for enhanced closure of skin injuries. Int J Pharm Pharm Sci 2014;6:542-6.

16. Sanket D, Priyanka R, Rahul U, Tanvi T, Manoj A. Mucoadhesive drug delivery systems-an unusual maneuver for site-specific drug delivery system. Int J Pharm Sci 2011;2:132-52.

17. Surya N, Adhikari R, Bhabani SN, Amit K, Mohanty B. Formulation and evaluation of buccal patches for delivery of atenolol. AAPS PharmSciTech 2010;11:1038-44.

18. Smart DJ. Drug delivery using buccal adhesive systems. Adv Drug Delivery Rev 1993;11:253-70.

19. Shinkar DM, Dhake AS, Setty CM. Drug delivery from the oral cavity: A focus on mucoadhesive buccal drug delivery systems. J Pharm Sci Tech 2012;66:466-500.

20. Pankil GA, Patel MR, Patel NM. A review article on mucoadhesive buccal drug delivery system. Int J Pharm Res Dev 2011;3:159-73.

21. Patel KV, Patel KR, Patel MR, Patel NM. A review article on mucoadhesive buccal drug delivery system: an overview. Int ] Pharm Bio Arch 2011;2:600-9.

22. Amir HS. Buccal mucosa as a route for systemic drug delivery: a review. J Pharm Pharm Sci 1998;1:15-30.

23. Felipe PF, Amanda CF, Said GCF, Jorg B, Humberto GF Manufacture and characterization of mucoadhesive buccal films based on pectin and gellan gum containing triamcinolone acetonide. Int J Polym Sci 2018;1:1-10.

24. Bindu MB, Zulkar NK, Ravinder N, David B. Mucoadhesive drug delivery system: an overview. J Adv Pharm Tech Res 201;1:381-407

25. Priya VB, Kanchan P, Upadhye, Gouri D. Formulation and evaluation of fast dissolving oral melt-in-mouth of Lorazepam for sublingual use. J Pharm Pharm Sci 2016;5:763-75.

26. Jaleh V, Farzin F, Erfaneh G. Formulation optimization and in vitro evaluation of rapid disintegrating and mucoadhesive sublingual tablets of lorazepam. Formacia 2015;63:234-45.

27. Navneet V, Pronobesh C. Preparation of mucoadhesive patches for buccal administration of metoprolol succinate: in vitro and in vivo drug release and bioadhesion. Trop J Pharm Res 2012;11:9-17.

28. Gathwala G, Goel M, Singh J, Mittal K. Intravenous diazepam, midazolam and lorazepam in acute seizure control. Indian J Pediatr 2012;79:327-32.

29. Aswathy N, Vidhya KM, Saranya TR, Sreelakshmy KR, Sreeja $\mathrm{CN}$. Mucoadhesive buccal patch of cefixime trihydrate using biodegradable natural polymer. Int J Pharm Sci 2014;6:366-71.

30. Gomez Guillen MC, Begona G, Lopenz Cabullero ME, Montero P. Functional and bioactive properties of collagen and gelatine from alternative sources: a review. Foodhyd 2011;25:1813-27.

31. Puglia C, Bonina F, Trapuni G, Franco M, Ricci M. Evaluation of in vitro percutaneous absorption of lorazepam and clonazepam from hydroalcoholic gel formulations. Int J Pharm 2001;28:79-87.

32. Nazila SM, Montakarn C, Thomas PJ. The use of mucoadhesive polymers in buccal drug delivery. Adv Drug Delivery Rev 2005;57:1661-91.

33. Presland RB, Dale BA. Epithelial structural proteins of the skin and oral cavity: functionin health and disease. Crit Rev Oral Biol Med 2000;11:383-408.

34. Walker DM. Oral mucosal immunology: an overview. Ann Acad Med Singapore 2004:33:27-30.

35. Wolfgang W, Natalie L, Claudia M, Alexander W, Michal S. Identification of lorazepam and slidenafil as examples for the application of LC/ionspray-MS and MS-MS with mass spectra library searching in forensic toxicology. Forensic Sci Int 2000;113:339-44

36. Nafee NA, Boraie MA, Ismail FA, Mortada LM. Design and characterization of mucoadhesive buccal patches containing cetylpyridinium chloride. Acta Pharmaceutica 2003;53:199-212.
37. Nafee NA, Ismail FA, Mortada LM, Boraie MA. Mucoadhesive buccal patches of miconazole nitrate: in vitro/in vivo performance and effect of aging. Int J Pharm 2003;264:1-14

38. Burgalassi S, Panichi L, Saettone MF, Jacobsen J, Rassing MR. Development and in vitro/in vivo testing of mucoadhesive buccal patches releasing benzydamine and lidocaine. Int J Pharm 1996;133:1-7.

39. Vishnu MP, Bhupendra GP, Madhabhai MP. Design and characterization of chitosan containing mucoadhesive buccal patches of propranolol hydrochloride. Acta Pharma 2007;57:61-72.

40. Patel RS, Poddar SS. Development and characterization of mucoadhesive buccal patches of salbutamol sulfate. Curr Drug Delivery 2009;6:140-4.

41. Kaur A, Kaur G. Mucoadhesive buccal patches based on interpolymer complexes of chitosan-pectin for delivery of carvedilol. Saudi Pharm J 2012;20:21-107.

42. Perioli L, Ambrogi V, Angelici F, Ricci M, Giovagnoli S, Cappuccella $\mathrm{M}$, et al. Development of mucoadhesive patches for buccal administration of ibuprofen. J Controlled Release 2004;99:73-82.

43. Morales JO, McConville JT. Manufacture and characterization of mucoadhesive buccal films. Eur J Pharm Biopharm 2011;77:187-99.

44. Semalty M, Semalty A, Kumar G. Formulation and characterization of mucoadhesive buccal films of glipizide. Indian J Pharm Sci 2008;70:43-108.

45. Nafee NA, Ismail FA, Boraie NA, Mortada LM. Mucoadhesive delivery systems I Evaluation of mucoadhesive polymers for buccal tablet formulation. Drug Dev Ind Pharm 2004;30:985-93.

46. Gupta A, Garg S, Roop Krishen K. Measurement of bioadhesive strength of mucoadhesive buccal tablets: design of an in vitro assembly. Indian Drugs 1993;30:152-5

47. Deepak S, Dipika M, Gilphy P, Ravish R, Shanu B, Manisha S, et al. Formulation and optimization of nanoparticles for intranasal delivery of lorazepam using box-Behnken design: in vitro and in vivo evaluation. Bio-Med Res Int 2014:14. http://dx.doi.org/10.1155/2014/156010

48. Amit AK, Vandana BP. Development and evaluation of lorazepam microemulsions for parenteral delivery. AAPS PharmSciTech 2008;9:966-71.

49. Trissel LA, Xu QA. Physical and chemical stability of palonosetron hydrochloride with lorazepam and midazolam hydrochloride during stimulated Y-Site administration. Int J Pharm Compd 2005;9:235-307.

50. Ataurrahmann F, Rsale, Ansari H. Formulation development and evaluation of flexible polymeric topical antifungal film. Int J adv Pharm Med Bioallied Sci 2015;3:137-41.

51. Foox M, Zilberman M. Drug delivery from gelatine based systems. Expert Opin Drug Delivery 2015;12:1547-63.

52. Sahar S, Soheli B. New formulation and approach for a mucoadhesive buccal film of rizatriptan benzoate. Prog Biomater 2017;6:175-87.

53. Ashutosh R, Prabhakara P, Akhilesh D. Design and evaluation of buccal patches containing combination of hydrochlorothiazide and atenolol. Int J Appl Pharm 2018;10:105-12.

54. Parmar VJ, Lumbhani AN, Vijayalakshmi P, Sajal J. Formulation development and evaluation of buccal films of carvedilol. Int J Pharm Sci Res 2010;1:149-56.

55. Lakshmana MG, Raghuvamsi V, Tirumala devi N, Narendra B, Sravya C, Masthaniah $\mathrm{K}$, et al. Design and evaluation of diclofenac sodium buccal mucoadhesive film by solvent casting technique. Int J Pharm Sci Res 2014;5:1767-75.

56. Gorakh JD, Durgacharan AB, John ID. Formulation and evaluation of fast dissolving buccal patch of olmesartan medoxomil. Asian J Biomed Pharm Sci 2013;3:51-5.

57. Himabindhu P, Krishna MC, Nagaraj B. Design and in vitro characterization of mucoadhesive buccal patches of duloxetine. Int J Pharm Pharm Sci 2017;9:52

58. Marina K, Narayana C, Vijayanarayana K, Prabhakara P. In vitro and In vivo evaluation of chitosan buccal films of ondansetron hydrochloride. Int J Pharm Investig 2011;1:164-71.

59. Indira $\mathrm{M}$, Srujana $K$. Mucoadhesive buccal films of glibenclamide: development and evaluation. Int J Pharm Investig 2011;1:42-57. 
60. Raghavendra R, Sunil F, Keyur P. Formulation and in vitro evaluation of mucoadhesive buccal patches containing zolmitriptan using gel-forming polymers. Der Pharmacia Sinica 2012;3:47-57.

61. Sumendra B, Mayank B, Gopal G. Preparation and evaluation of buccoadhesive patches of an antihypertensive drug. Am J Phytomed Clin Ther 2013;1:240-55.

62. Pooja S, Dharmendra S. Formulation and evaluation of mucoadhesive buccal patch of timolol maleate. Am J Pharm Tech Res 2017;7:335-48.

63. Shivhare UD, Vyawahare AM, Bodele SB. Formulation and evaluation of mucoadhesive buccal patch for the treatment of migraine. Int J Pharm Chem Biol Sci 2013;2:1812-8.
64. Pradeep KK. Formulation and in vitro evaluation of bilayered buccal patches of a proton pump inhibitor. Am J Adv Drug Delivery 2013;1:651-62.

65. Sreeja CN, Mabble SJ, Anoop KR. In situ gel: an innovative approach for safe and sustained nasal drug delivery. Int J Pharm Sci Rev 2014;24:1-7.

66. Aiswarya MU, Keerthana R, Revathy BM, Lakshmi VS, Sreeja CN. Cryptosomes: A revolutionary breakthrough in novel drug delivery. Int J Appl Pharm 2019;11:7-13.

67. Revathy BM, Lakshmi VS, Aiswarya MU, Keerthana R. Porphysomes-a paradigm shift in targeted drug delivery. Int J Appl Pharm 2018;10:1-6.

68. Paul A, Fathima M, Nair SC, Antony NV. Intranasal in situ gelling system of lamotrigine using ion activated mucoadhesive polymer. Open Med Chem J 2017;11:222-44. 